\title{
The Nature of Manual Dexterity and its Relation to Vocational Testing.
}

\author{
By Prof. T. H. Pear, J. N. Langdon, and Edna M. Yates.
}

RECENT research to discover suitable tests of manual dexterity has concentrated upon two kinds, the sample or 'trade' test, and the 'analytic' test. The first kind explains itself; the second attempts to analyse the candidate's manual dexterity into simpler and, if possible, unitary dexterities. It then separately examines his capacities for them. ${ }^{1}$

To the immediately practical mind the sample test has advantages so obvious that it would appear foolish to supplant it. But the defects of its virtues are many. Though it measures a candidate's ability in the actual occupation for which he is wanted, it leaves quite undetermined a beginner's capacity for learning such a job; and ability is often acquired only at the expense of time and money. Except, therefore, for low-grade dexterities, the sample test will be useless for selecting those persons who, though they are not yet proficient in a particular job, are specially fitted for it. Furthermore, the risk of spoiling tools or machinery, and the physical danger in allowing potential failures to undertake complicated sample tests, are obvious.

Of these defects, the failure of the sample tests to discover capacity, as distinct from ability, is of chief psychological interest. For though such a failure must obviously occur with high-grade, complex skills, it is not certain that a sample test of low-grade dexterity, comprising only a few simple movements, would not test capacity.

Dissatisfaction with the sample test has encouraged attempts to discover simple or unitary capacities underlying more complicated forms of dexterity. Generally speaking, testing the simple muscular dexterities in the analytic procedure is far from simple, and requires a trained psychologist. This necessity, however, is admitted in many quarters. In Germany especially the analytic test is much in favour. ${ }^{2}$

Yet there is little evidence concerning the important question, whether the 'simple' factors which, after an analysis of any instance of muscular dexterity, are chosen to be tested, really compose that dexterity. While it seems that in a highly complicated skill the whole performance is not the mere sum of its parts, this seems less certain of a low-grade skill, which appears to be merely the simultaneous or successive combination of simple movements. For what is actually known concerning the functional interrelationships of the simpler motor capacities suggests that they are not so intimate as was formerly supposed. Perrin, ${ }^{3}$ Muscio, ${ }^{4}$ and the present writers ${ }^{5}$ have found very low correlations between simple motor performances. The manner in which they are 'tied together' is not certainly known. ${ }^{6}$ As Prof. Edward L. Thorndike has pointed out from the result of experiments, "We see the possibility of a disciplinary effect ${ }^{7}$ where superficial observation would have expected none, the difficulty of transfer in a case where speculative and verbal thinking would have assumed that it was easy, and, in general the ignorance that we suffer from, concerning the internal constituents of almost every act of learning."

Obviously, therefore, in searching for a test of

1 Cf. Prof. C. Burt's chapter on vocational tests in "Industrial Administration," edited by Muscio.

2 Cf. F. Giese. "Psychotechnische Eignungsprüfungen" (Halle)

3 "An Experimental Study of Motor Ability," Journal of Experimental Psychology, 1921.

" "Motor Capacity with special reference to Vocational Guidance," British Journal of Psychology, October 1922.

"In an unpublished report to the Industrial Fatigue Research Board. - Cf. Pear, "Skill in Work and Play," pp. 22-3.

I.e. transfer of training from one performance to a different one. capacity for manual dexterity (low-grade skill) it is necessary to examine, in the light of any procurable evidence, the relative claims of the sample and analytic tests.

\section{Experimental Tests used.}

The investigation described below was carried out with the support of the Industrial Fatigue Research Board in the psychological laboratory of the University of Manchester. It concerned a simple instance of manual dexterity closely resembling an actual process in the chain-assembling industry. Its main aim was to discover whether there is any transfer of training acquired in one kind of dexterity, to another in which there has been no such training. ${ }^{8}$ It offers evidence, however, bearing upon the validity of the "analytic' procedure in the vocational testing of manual dexterity.

A group of 28 subjects was trained intensively for eight days on an operation in which links were removed from and others replaced on spindles, the handling of which involved the rotation of a turntable. Improvement in general was more than fifty per cent. of the initial score. Before training was commenced, the performance of each subject was measured in various tests designed to show the presence or absence of transfer. These tests were selected in accordance with an observational and introspective analysis of the operation with the links and spindles described above. It will be seen from the following that many of them are simple tests of manual dexterity and may be of some interest in connexion with vocational selection.

(1) Match insertion.-The match-insertion board used in psychological testing was employed. Matches were taken one at a time from a standard position and inserted in the small holes, the score being the number of matches inserted in a two-minute period.

(2) Placing matches in a box.- Thirty matches were arranged in a row on the table, and were picked up one at a time and placed neatly in a match-box. The score was the time taken.

(3) Placing rings on a rod.-The subject took rings, one at a time, from a bowl, and slipped them over a rod. The score was the number dealt with in two minutes.

These three tests were performed with right and left hands separately.

(4) Steadiness. - The apparatus is described in Whipple's "Manual of Mental and Physical Tests," vol. 1, p. 152. It is the usual tracing board, with a slit bounded by converging metal strips. Along one edge is mounted a millimetre scale. The subject was instructed to draw the stylus along the slit without making contact with the sides. At the first contact the subject stopped and repeated the process. This was repeated eleven times. The score in each case was the distance traversed before contact, and the final score was the median of these eleven.

(5) Steadiness. - The metal plate pierced with holes of different diameters, as described in Whipple's "Manual," was employed. The subject had to hold the stylus in each hole in turn for 15 seconds. The total time before contact was made was recorded, and the score was the median of 7 trials.

(6) Arm movement.-The blindfolded subject was required to make a movement of the arm, the extent

${ }^{8}$ J. N. Langdon and Edna M. Yates, Memoirs and Proceedings of the Manchester Literary and Philosophical Society, vol. 72, and "An Experimental Investigation into the Transfer of Training in Skilled Performances." British Journal of Psychology, April 1928. 
of which was measured by apparatus which precluded all save a rotary movement. He was then instructed to make another movement of the same extent as before. The score was the coefficient of variation of ten such trials.

(7) Moede's impulse meter.-The subject holds a hammer in his right hand and is instructed to strike a specially devised anvil. The force of the blow is measured on a scale. (An illustration is given in the apparatus catalogue of E. Zimmermann, Leipzig.) $\mathrm{He}$ is then told to strike the anvil again with just the same force as before. He repeats this ten times in all. Here again the score was the coefficient of variation.

(8) A group test of intelligence, No. 33 in the National Institute of Industrial Psychology's series.

\section{Provision of Adequate Incen'ives.}

It is a valid criticism of many experiments upon the acquirement of skill that one is uncertain if the motives urging the learners to try their best are adequate. Since many of the tasks are very simple and may become monotonous, boring, or irksome, the stimulus is lacking which a recognised test of intelligence naturally offers to university undergraduates or graduates, who are the usual volunteer 'subjects' for such experiments. ${ }^{9}$ The Industrial Fatigue Research Board made it possible to supply a financial motive for adequate performance; the subjects, unemployed boys aged fifteen to eighteen years, from the local Labour Exchange, were employed full time. They were paid a minimum wage of $12 s$. per week plus a piece-rate depending upon daily performance. A similar piece-rate was paid for success in the 8 tests described. The work therefore was to them extremely important. They were under close observation all the time. It is thus perfectly certain, both from their behaviour and from their own account of the work, that the incentive to try hard was adequate.

The correlations obtained between each of the tests and the abilities in the operation with the links and spindles at the end of 8 days' training will now be given. In addition, the scores of the first, second, and third periods of ten minutes' practice, and also the mean score per period of the first day's training, were correlated with the mean score per period of the last day's training.

The table shows that the supposedly analytic tests show little correlation with the practised operation. The coefficients are all lower than that between rank in the second period of ten minutes' practice and rank in the mean performance on the final day of training. The coefficient derived from the second period of ten minutes' practice when correlated with the practised operation is identical with that from the first day's practice when correlated with the operation. It is higher than that derived from the first period of 10 minutes' practice when correlated with the final practised ability in the operation with the links and spindles.

\section{CONCLUSION.}

In this investigation, involving simple manual dexterity or low-level skill of a kind similar to that required in industry, the present experimental results do not support the hypothesis of a close relation between the simple performances in the analytic tests and the more complex performance involved in the practised operation itself. This agrees with the major result of the investigation reported else-

' Cf. F. C. Bartlett, “ Psychology and the Soldier," pp. 69-76; Burnett and Pear, "Motives in Acquiring Skill," British Journal of Psychology, vol. 16, pp. 77-85. where, that there is no evidence for transfer of training from the practised operation to performances in the 'simple' tests.

Results pointing in a similar direction but obtained upon a smaller number of subjects have been recently published by Dr. Hans Kellner. ${ }^{10}$

If such results are further confirmed by experiment they would justify the use, as a selective test for an occupation at a low level of skill, of a sample 'try out' in the operation itself. But this would have to be done only after an initial trial had been given to secure adaptation to the experimental conditions. Even

Correlation with AbILIty in the Operation with thy Links and Spindles at end of 8 Days' Practice.

\begin{tabular}{|c|c|c|}
\hline Test. & $\begin{array}{l}\text { Correlation } \\
\text { coefficient. }\end{array}$ & $\begin{array}{c}\text { Probable } \\
\text { error. }\end{array}$ \\
\hline $\begin{array}{l}\text { First 10-min. period in the opera- } \\
\text { tion with links and spindles }\end{array}$ & $0 \cdot 43$ & $0 \cdot 11$ \\
\hline $\begin{array}{l}\text { Second } 10-\mathrm{min} \text {.period in the opera- } \\
\text { tion with links and spindles }\end{array}$ & $0 \cdot 57$ & $0 \cdot 09$ \\
\hline $\begin{array}{l}\text { Third } 10 \text {-min. period in the opera- } \\
\text { tion with links and spindles }\end{array}$ & $0 \cdot 52$ & $0 \cdot 10$ \\
\hline $\begin{array}{l}\text { Mean score of first day in the } \\
\text { operation with links and spindles } \\
\text { (sixteen 10-min. periods). }\end{array}$ & 0.57 & 0.09 \\
\hline Match insertion. R. hand . & $0 \cdot 24$ & $0 \cdot 13$ \\
\hline Match insertion. L. hand . & $0 \cdot 24$ & $0 \cdot 13$ \\
\hline Placing matches in box. R. hand . & $0 \cdot 46$ & $0 \cdot 11$ \\
\hline Placing matches in box. L. hand . & $0 \cdot 16$ & 0.13 \\
\hline Placing rings on rod. R. hand . & $0 \cdot 30$ & $0 \cdot 12$ \\
\hline Placing rings on rod. L. hand . & $0 \cdot 28$ & $0 \cdot 12$ \\
\hline Steadiness (1). & $0 \cdot 34$ & $0 \cdot 12$ \\
\hline Steadiness (2). & $0 \cdot 06$ & $0 \cdot 13$ \\
\hline Impulse meter & $0 \cdot 23$ & $0 \cdot 13$ \\
\hline Arm movement & $0 \cdot 22$ & $0 \cdot 13$ \\
\hline Intelligence . & $0 \cdot 21$ & $0 \cdot 13$ \\
\hline
\end{tabular}

here it must be emphasised that the correlation between the second (adapted) performance and the final (practised) ability is very low.

Despite this fact, however, a 'try-out' on the operation appears to be fairly useful in diagnosis. For in the present investigation, after a preliminary trial for adaptation, it was found that of those boys who were in the upper half of the distribution in the 'try-out,' 86 per cent. were in the upper half of the distribution on the last day of training.

The investigation also throws light upon another common and natural view not supported by the present figures. This opinion is that in selection for a performance involving low-grade skill, an error in the choice of operatives would not be serious.

In the present investigation, at the conclusion of the 8 days' training, the difference between the best and the worst performance was 126 links per period. There were 16 such periods per day. Therefore, even in this short working-day, between the best and the worst performance there was an average difference of more than 2000 links. In other words, the practised ability of the worst worker was only 64 per cent. of the best. This offers strong evidence of the need for selection even in occupations requiring a low degree of skill. The present figures favour the 'sample' as against the 'analytic procedure' for selecting operatives for such occupations.

10 Psychotechnische Zeitschrift, December 1927, pp. 153-161.

No. 3054, VoL. 121] 